\title{
Perbandingan Deiksis pada Dua Buku Ajar: Analisis Kontrastif BIPA dan Bahasa Inggris
}

\author{
Destiani, Andayani, \& Muhammad Rohmadi \\ Universitas Sebelas Maret \\ destiani@student.uns.ac.id
}

How to cite (in APA Style): Destiani, Andayani, \& Rohmadi, M. (2018). Perbandingan deiksis pada dua buku ajar: analisis kontrastif BIPA dan bahasa Inggris. Jurnal Pendidikan Bahasa dan Sastra, 18(2), doi: 10.17509/bs_jpbsp.v18i2.15505

Article History: Received (03 August 2018); Revised (25 September 2018); Accepted (01 October 2018)

Journal homepage: http:// ejournal.upi.edu./index.php/BS_JPBSP

\begin{abstract}
Abstrak: Bahasa Indonesia menjadi bahasa asing bagi mahasiswa asing di Universitas Sebelas Maret. Mahasiswa asing yang mampu berbahasa Inggris mengalami kesulitasn saat menggunakan deiksis dalam memproduksi serta memahami kalimat. Penelitian ini bertujuan membandingkan penggunaan deiksis dalam buku ajar Bahasa Indonesia bagi Penutur Asing (BIPA) dan buku ajar bahasa Inggris. Jenis penelitian menggunakan deskriptif kualitatif dengan pendekatan analisis kontrastif. Penggunaan software AntConc versi 3.4.5 untuk memperoleh data korpus dari buku BIPA. Konkordansi data yang dianalisis dibandingkan dengan data deiksis dalam buku ajar bahasa Inggris. Hasil penelitian menunjukkan deiksis antara kedua bahasa tersebut memiliki perbedaan dari segi posisi, bentuk, dan penggunaan. Deiksis dalam bahasa Indonesia dapat digunakan sebelum dan sesudah kata benda, sedangkan deiksis bahasa Inggris hanya digunakan di sebelum kata benda atau kata kerja. Bentuk deiksis dalam bahasa Inggris dapat berubah sesuai dengan rujukan benda yang bersifat tunggal dan jamak. Berdasarkan hasil penelitian, pengajar dapat menjelaskan secara konkret tentang deiksis dengan membawa obyek rill atau gambar dalam materi pembelajaran di kelas BIPA agar pembelajaran lebih efektif dan komunikatif.
\end{abstract}

Kata kunci: bahasa Indonesia; BIPA; deiksis; korpus; mahasiswa asing

\section{Deixis Comparison of Two Textbooks: Contrastive Analysis of BIPA and English}

\begin{abstract}
Indonesian language is a foreign language at Sebelas Maret University for students from abroad. Foreign students who communicate with English encounter difficulty to understand and use deixis. This study tried to contrast deixis on two textbooks, Bahasa Indonesia bagi Penutur Asing (BIPA)/Indonesian for foreigner and English textbook. The study was conducted through qualitative study with contrastive analysis. AntConc version 3.4.5 was used to identify deixis corpus from BIPA textbook. The concordance from the BIPA textbook was compared with sentences on the English textbook. The analysis found that deixis from those textbooks were different in term of position, form and use. Indonesian deixis can either precede or follow a noun or verb while English deixis appeared only before a noun or verb. When coming together with plural noun, English deixis changes in the form, meanwhile Indonesian's is not. Based on this study, BIPA teachers are suggested to bring concrete samples during teaching deixis.
\end{abstract}

Keywords: Indonesian language; BIPA; deixis; corpus; foreign student 


\section{PENDAHULUAN}

Bahasa Indonesia kini banyak dipelajari orang asing. Tidak kurang dari 46 negara seperti Kanada, Amerika, Australia, Jepang, Rusia, Jerman, dan Afrika mempelajari bahasa Indonesia. Bahkan, bahasa Indonesia dijadikan bahasa populer ke-4 di Australia (Andayani, 2011). Kondisi tersebut adalah upaya menginternasionalisasikan bahasa Indonesia di kancah dunia. Langkah strategis internasionalisasi bahasa Indonesia melalui pengajaran BIPA di universitasuniversitas, baik dalam maupun luar negeri. Hal tersebut sesuai pernyataan Muliastuti (2016,p. 8) bahwa internasionalisasi bahasa Indonesia ditingkatkan melalui pengajaran BIPA yang didukung oleh semua lembaga yang relevan. Hal demikian memberikan dampak positif yaitu jumlah penutur dan area penggunaan bahasa Indonesia akan terus bertambah.

Program BIPA merupakan pembelajaran bahasa Indonesia dengan subjek mahasiswa asing. Jadi, bahasa Indonesia merupakan bahasa asing bagi mahasiswa BIPA. Pembelajaran BIPA menjadikan orang asing mampu dan menguasai bahasa Indonesia (Kusmiatun, 2016,p.1). Mahasiswa asing tersebut biasanya belum mengerti dasar dan tatabahasa bahasa Indonesia, tetapi tertarik untuk mempelajarinya. Mahasiswa asing yang belajar bahasa Indonesia di Universitas Sebelas Maret (UNS) sebagian besar melalui Beasiswa Darmasiswa. Darmasiswa merupakan program beasiswa yang diberikan kepada mahasiswa asing yang tertarik bahasa dan budaya Indonesia. Mahasiswa asing berasal dari berbagai negara yang memiliki hubungan diplomatik dengan Indonesia. Pelaksanaan program BIPA ini diprakarsai oleh Kementerian Pendidikan dan Kebudayaan Republik Indonesia

(http://darmasiswa.kemdikbud.go.id).

Bahasa Indonesia sebagai bahasa asing merupakan bahasa yang dipelajari setelah bahasa pertama dikuasai. Artinya, ini pun berlaku pada bahasa kedua, ketiga, ataupun keempat sehingga tidak menutup kemungkinan bahasa asing seseorang ialah bahasa kedua yang dikuasai. Seperti yang dinyatakan Ellis (1986,p.3) bahwa pemerolehan bahasa kedua dapat dijabarkan sebagai cara seseorang mempelajari suatu bahasa, selain bahasa ibunya, baik di dalam maupun di luar kelas.

Unsur gramatikal menjadi salah satu aspek penguasaan mahasiswa asing dalam belajar BIPA. Dengan memahami perangkat kohesi, kegramatikalan sebuah bahasa menjadi padu. Hal tersebut sesuai dengan pernyataan Tanskanen (2006) bahwa kesatuan wacana hanya dapat dilakukan melalui penggunaan perangkat kohesif. Perangkat kohesi mengacu pada fitur linguistik yang membantu membuat urutan kalimat teks (Alarcon, \& Morales, 2011).

Deiksis adalah fitur kohesi sebagai penanda dari konteks ruang yang bersifat sementara dan bentuk pengalaman dari subyektif seseorang (Levinson, 1983; Green, 2015). Sementara itu, Putrayasa (2014) menyatakan deiksis adalah bentuk bahasa, baik kata maupun lainnya yang berfungsi sebagai penunjuk hal atau fungsi tertentu di luar bahasa. Dengan kata lain, sebuah bentuk bahasa bisa dikatakan bersifat deiksis apabila acuan/ rujukan/ referennya berpindah-pindah atau berganti-ganti pada siapa yang menjadi pembicara dan bergantung pula pada saat dan tempat dituturkannya kata-kata tersebut. Fenomena deiksis merupakan cara yang paling jelas untuk menggambarkan hubungan antara bahasa dan konteks dalam bahasa. Cummings (2007) menambahkan deiksis mencakup ungkapan-ungkapan dari kategori-kategori gramatikal yang memiliki keragaman sama banyaknya seperti kata ganti dan kata kerja, menerangkan berbagai entitas dalam konteks sosial, linguistik, atau ruang waktu ujaran yang lebih luas. Berdasarkan pendapat para pakar di atas, sintesis dari deiksis adalah sebuah kata atau lebih yang merujuk pada bagian dari bahasa dan memiliki konteks yang bergantung pada waktu, jarak, dan pembicara/ penulis yang menyampaikan informasi, baik lisan maupun tulisan. 
Secara aturan, bahasa tertulis senantiasa melibatkan konteks dan acapkali rujukan kata ganti tidak jelas mengacu pada siapa sehingga terjadi masalah interpretasi bagi pembaca (Fairclough dan Wodak, 2008). Dalam konteks tatap muka secara langsung, ujaran pembicara dapat dengan mudah ditafsirkan lawan bicara sebab rujukan dapat dijelaskan secara langsung dan bisa jadi jarak obyek dengan pembicara dekat (O`Keefe, Clancy, dan Adophs, 2011). Deiksis dibagi menjadi tiga jenis, yakni pembicara/ penulis (orang), waktu ujaran (waktu), dan lokasi (ruang). Contoh dari masing-masing bentuk ialah kata ganti orang (saya, Anda), demonstratif (ini, itu), dan keterangan waktu atau tempat (sekarang, di sini, di situ) (Mulderrig, 2012).

Mahasiswa asing di UNS diharuskan untuk menguasai bahasa Indonesia, khususnya bidang akademik. Mahasiswa akan lebih mudah berkomunikasi setelah menguasai bahasa Indonesia terutama dalam proses pembelajaran dan penyelesaian tugas di kampus (Saddhono, 2012). Deiksis ini dan itu tersaji dalam buku ajar BIPA. Penggunaan deiksis ini dan itu adalah hal baru bagi mahasiswa asing yang berada di level pemula. Berdasarkan hasil observasi informal, mahasiswa asing yang berlatar belakang berbahasa Inggris mengalami kesulitan untuk menggunakan deiksis ini dan itu. Perbedaan penggunaan deiksis bahasa Indonesia dengan bahasa Inggris menyulitkan dan membingungkan mahasiswa. Kalimat di bawah ini merupakan hasil riset Itaristanti (2016) terkait kesulitan mahasiswa asing menggunakan deiksis bahasa Indonesia.

Kota jakarta memiliki banyak tempat wisata seperti taman mini indonesia indah merupakan suatu kawasan taman wisata bertema budaya Indonesia di jakarta timur. Area seluas kurang lebih 150 hektare.

Berdasarkan kalimat di atas, penggunaan kata-kata Area seluas kurang lebih 150 bektare belum jelas acuannya dan hubungannya dengan kalimat pertama sehingga perlu adanya kata yang memadukan dengan kalimat pertama. Pada kata area dapat ditambahkan kata taman dan deiksis itu sehingga rujukan jelas. Perbaikan kalimat tersebut sebagai berikut.

Kota jakarta memiliki banyak tempat wisata seperti taman mini indonesia indah merupakan suatu kawasan taman wisata bertema budaya Indonesia di jakarta timur. Area taman itu seluas kurang lebih 150 hektare.

Pada latar belakang menunjukkan kesulitan mahasiswa asing dalam penggunaan deiksis. Hal ini mungkin takkan terjadi dalam pembelajaran deiksis bahasa Inggris. Adanya perbedaan bentuk dan penggunaan antara deiksis kedua bahasa tersebut membuat peneliti tertarik untuk mengkaji lebih dalam. Konkordansi yang ditampilkan dari data korpus buku ajar BIPA dan kalimat-kalimat berdeiksis dalam buku ajar Bahasa Inggris akan terlihat kontras di antara kata penunjuk tersebut. Dengan demikian permasalahan dalam penelitian ini adalah (1) bagaimanakah perbedaan bentuk deiksis pada buku ajar BIPA dan Bahasa Inggris?, dan; (2) bagaimanakah perbedaan penggunaan deiksis dari kedua buku ajar tersebut? .

\section{METODE}

Penelitian ini menggunakan jenis deskritif kualitatif dengan pendekatan analisis kontrastif. Analisis kontrastif meneliti perbedaan di antara sepasang bahasa (bagian kecil dari bahasa) terkait dengan latar belakang persamaan dengan tujuan memberikan masukan pada ilmu terapan, seperti pengajaran bahasa asing dan penelitian penerjemahan (Lado, 1957). Lado mengkalim bahwa kita dapat memprediksi dan menjelaskan pola-pola yang hendak mengakibatkan kesulitan dalam pembelajaran dan pola-pola yang tidak akan menyulitkan dengan cara membandingkan secara sistematis bahasa dan budaya asing dengan bahasa dan budaya mahasiswa. 
Sumber data dalam penelitian menggunakan dua buku, yakni buku ajar BIPA Sababatku Indonesia (SI) diterbitkan Kementerian Pendidikan dan Kebudayaan Indonesia dan buku ajar Essential Grammar in Use (EGU) diterbitkan Cambridge University Press.

Buku ajar SI terdiri atas sepuluh unit, yakni Menyapa, Berkenalan, Keluargaku, Selamat Ulang Tabun, Jalan-Jalan, Penyayang Binatang, Petunjuk. Arah, Kegiatan Sehari-Hari, Rumah Santi, dan Lagu Populer Indonesia. Buku ajar ini diperoleh dari website Badan Pengembangan dan Pembinaan Bahasa Kementerian Pendidikan dan Kebudayaan dalam bentuk $p d f$. Kemudian, buku disalin (copy) dan tempel (paste) dalam bentuk notepad $t x t$. Kemudian, file txt. dimasukkan ke dalam program AntConc versi 3.4.5.

Software AntConc versi 3.4.5 merupakan program komputer yang digunakan untuk meneliti konkordansi buku ajar SI. AntConc menganalisis sejumlah konkordansi dari hasil kerjanya
(Anthony, 2014). Setelah dioperasikan, dilihat jumlah penggunaan deiksis ini dan itu melalui menu wordlist serta frekuensi dari masing-masing deiksis. Kemudian, pada menu konkordansi, dilakukan save out data dalam bentuk file excel. Kemudian, melakukan penghitungan jumlah masingmasing penggunaan deiksis ini dan itu. Setelah itu, penulis membandingkan kedua deiksis ini dan itu yang terdapat dalam buku ajar BIPA SI dan buku ajar EGU.

\section{HASIL DAN PEMBAHASAN}

Deiksis ini dan itu pada buku ajar SI

Berdasarkan hasil kerja software AntConc versi 3.4.5 diperoleh jumlah keseluruhan kata pada buku ajar BIPA SI sebanyak 17.173 dengan jenis kata sebanyak 2.170. Dari jumlah tersebut, deiksi ini sebanyak 271, sedangkan deiksis itu sebanyak 38. Penggunaan kedua kata ini dan itu terdapat perbedaan jumlah yang sangat jauh. Hasil temuan dari software AntConc 3.4.5 disampaikan pada tabel berikut ini.

Tabel 1. Penggunaan Deiksis Ini dan Itu pada Buku Ajar BIPA SI

\begin{tabular}{cc}
\hline Deiksis & Jumlah \\
\hline ini & 271 \\
\hline itu & 38
\end{tabular}

Penggunaan deiksis ini dan itu ditemukan dalam buku ajar BIPA SI dengan posisi atau letak deiksis yang berbeda-beda. Deiksis tersebut ada yang mendahului kata benda atau kata kerja dan mengikuti kata benda.

\section{a. Deiksis sebelum kata benda atau kata kerja}

Berikut ini penggunaan deiksis yang mendahului kata benda atau kata kerja.

(1) Ini adalah kamar tidur saya.

(2) Lalu, ini adik laki-laki saya.

(3) Yang ini ayah saya, namanya Aris.

Deiksis ini pada kalimat (1), (2), dan (3) menunjukkan penggunaan deiksis di awal kata benda dan kata kerja. Kalimat (1) deiksis ini di awal kalimat lalu diikuti kata kerja adalah kemudian kamar tidur saya sebagai pelengkap. Deiksis ini dalam kalimat mengacu pada kamar tidur. Sementara itu, pada kalimat (2) dan (3) deiksis ini digunakan sebelum kata benda yang masing-masing mengacu pada adik laki-laki saya dan ayah saya.

(4) Itu foto teman saya.

(5) Itu kakak perempuan saya. Namanya Eni.

(6) Semua orang yang ada di foto itu anggota keluargaku

Deiksis itu pada kalimat (4), (5), dan (6) sama-sama mengacu kata benda, masing- 
masing yakni foto, kakak perempuan, dan foto. Pada kalimat (4) dan (5) deiksis itu sebagai subyek kalimat. Akan tetapi deiksis itu pada kalimat (6) sebagai subyek yang diperluas karena adanya kata hubungan yang.

\section{b. Deiksis setelah kata benda}

Berikut ini adalah konkordansi deiksis ini dan itu yang mengikuti kata benda sebagai berikut.

(1) Setelah mengisi bensin, saya dan keluarga pergi makan di Pizza

Hut. Restoran ini ada di antara KFC dan McD.

(2) Makanan ini banyak dijual.

(3) Ulang tahun Anda tahun ini?

Deiksis dalam ketiga kalimat tersebut sama-sama mengikuti kata benda, yakni terdiri atas restoran, makanan, dan tahun. Pada kalimat (1) frasa restoran ini berfungsi sebagai subyek dan kalimat (2) frasa makanan ini sebagai subyek. Akan tetapi, pada kalimat (3) frasa tahun ini berperan sebagai obyek.

Berikut ini konkordansi pada penggunaan deiksis itu yang mengikuti kata benda sebagai berikut.

(4) Di atas meja kecil itu ada lampu duduk.

(5) Mobil itu bermesin diesel.

(6) Kucing dan anjing itu sangat lucu.

Deiksis dalam ketiga kalimat tersebut mengacu pada kata benda masingmasing terdiri atas meja kecil, mobil, dan kucing dan anjing. Pada kalimat (4) Di atas meja kecil itu ada lampu duduk deiksis itu bersamaan dengan frasa di atas meja kecil berperan sebagai subyek. Pada kalimat (5) Mobil itu bermesin diesel deiksis itu bersamaan degan kata benda mobil berperan sebagai subyek dan kalimat (6) Kucing dan anjing itu sangat lucu deiksis itu bersama dengan frasa kucing dan anjing sebagai subyek.

\section{c. Deiksis dengan acuan tunggal dan jamak}

Penggunaan deiksis ini dan itu pun dapat digunakan untuk mengacu pada kata benda tunggal dan jamak. Berikut ini contoh-contoh kalimat pada masing-masing penggunaan.

(1) Ini adalah Pak Badrun. Dia tua.

(2) Bagaimana bentuk meja itu?

(3) Para pahlawan itu dengan sungguh-sungguh untuk membela negara.

(4) Cari tahulah identitas orang dalam foto-foto berikut ini!

Pada kalimat (1) dan (2) merujuk pada kata benda tunggal masing-masing terdiri atas Pak Badrun dan meja, sedangkan pada kalimat (3) dan (4) deiksis itu merujuk pada benda jamak terdiri atas para pahlawan dan foto-foto. Jika dilihat pada kalimat (1) hingga (4) penggunaan deiksis ini dan itu yang merujuk pada benda tunggal sama dengan deiksis yang merujuk pada benda jamak. Penggunaan deiksis tidak ada perubahan bentuk. Akan tetapi, adanya pengulangan atau penggunaan kata sandang, seperti pada kalimat (3) dan (4). Pada kalimat (3) kata sandang para untuk mewakili kata benda jamak pablawan. Kata sandang tersebut menunjukkan makna jamak. Sementara itu, pada kalimat (4) adanya pengulangan kata benda foto menjadi foto-foto. Pengulangan kata benda tersebut merujuk pada kata jamak, yakni jumlah foto yang lebih dari satu buah. Dengan demikian, pada rujukan benda tunggal, tidak adanya perubahan bentuk deiksi, tetapi adanya pengulangan atau penambahaan kata sandang pada kata benda yang bersifat tunggal.

\section{Deiksis this dan that pada buku ajar EGU}

Pada buku Essential Grammar in Use (EGU) penggunaan deiksi ini (this) dan itu (that) tersaji dalam buku. Berikut ini 
penggunaan deiksis this (ini) dan that (itu) dalam buku EGU.

\section{a. Deiksis sebelum kata benda}

Contoh penggunaan deiksis this dan that sebelum kata benda sebagai berikut.

(1) This hotel is expensive, but it's very nice (p.42)

(Hotel ini mahal, tetapi sangat menyenangkan).

(2) Brian, this is Chris. (p.42) (Brian, ini adalah Chris).

(3) Hi Sarah, this is David. (p..42) (Hai Sarah, ini adalah David)

Ketiga kalimat di atas (1), (2), dan (3) menggunakan deiksis yang sama yaitu this. Penggunaan deiksis this pada kalimat (1) mengacu pada hotel kalimat (2) mengacu pada Chris, dan kalimat (3) mengacu pada David. Ketiga rujukan tersebut merupakan kata benda. Pada kalimat pertama, deiksis ini yang melekat bersama kata benda hotel berperan sebagai subyek, kemudian kalimat kedua deiksis this yang digunakan pada dialog berperan sebagai subyek, dan deiksis this pada kalimat ketiga berperan sebagai subyek yang digunakan pada kalimat dialog.

(4) Is that Sarah? (p.42) (Apakah itu Sarah?)

(5) That was a really nice meal. Thank you very much. (p.42) (Itu makanan yang sangat enak. Terima kasih banyak.) (menyatakan kegiatan lampau)

(6) I'm sorry, I forgot to phone you.' 'That's all right.' (p.42)

(Saya minta maaf, saya lupa menelpon kamu. Tidak apaapa.)

Tiga kalimat di atas (4), (5), dan (6) menggunakan deiksis that Pada kalimat (4) deiksis that (ini) mengacu pada kata Sarah yang disampaikan melalui kalimat tanya, sedangkan kalimat (5) deksis that mengacu pada makanan enak yang disampaikan pada waktu lampau. Kemudian, kalimat (6) deiksis that mengacu pada kesalahan lawan bicara yang tidak menelpon. Kalimat keenam merupakan kalimat dialog yang disampaikan penutur dan lawan tutur.

\section{b. Deiksis this dan that merujuk benda tunggal dan jamak}

Pada buku EGU pun terdapat penggunaan deiksis this dan that yang merujuk benda tunggal dan jamak.

(1) Dou you like this picture? (p.42) (Apakah kamu menyukai foto ini?)

(2) Do you like that picture? (p.42) (Apakah kamu menyukai foto itu?)

(3) These flowers are for you. (p.42) (Bunga-bunga ini untukmu.)

(4) Those apples look nice. Can I have one? (p.42)

(Apel-apel itu terlihat bagus. Bisakah saya meminta satu?)

Pada kalimat (1) tdan (2) terdapat penggunaan this dan that yang merupakan deksis ini dan itu. Deiksis this dan that samasama mengacu pada benda tunggal, yaitu foto. Akan tetapi, deiksis this merujuk keberadaan obyek yang dekat, sedangkan deiksis that merujuk pada keberadaan obyek yang jauh seperti pada kedua contoh di atas. Kemudian, kalimat (3) deiksis these merupakan deiksis yang digunakan untuk merujuk obyek jamak yaitu bunga-bunga. Deiksis these berubah bentuk dari deksis this karena rujukan benda jamak. Kemudian, kalimat (4) deiksis those merupakan deiksis yang digunakan untuk merujuk objek jamak yaitu apel-apel. Deiksis those berubah bentuk dari deiksis that karena rujukan benda jamak. Dalam bahasa Inggris, penggunaan deiksis this dan that digunakan untuk rujukan benda tunggal, sedangkan these dan those digunakan untuk rujukan benda yang bersifat jamak. Selain adanya perubahan bentuk deiksis karena rujukan benda tunggal dan jamak, kata benda yang bersifat jamak tidak diulang, seperti berlaku pada deiksi bahasa Indonesia. Hal ini sesuai dalam buku ajar yang disampaikan Murphy (2014,p.42) tentang penggunaan kata this dan that untuk 
rujukan kata benda tunggal dan these (ini) dan those (itu) untuk rujukan kata benda jamak.

Dalam bahasa Inggris, kata benda yang bersifat jamak, akhiran hurufnya bertambah atau berubah menjadi $-s$, -es, -ies, dan -ys bergantung pada akhiran bunyi kata. Kata-kata berakhiran bunyi $-r,-n$, $-e$, dan $-t$ ditambahkan $-s$, seperti this flower menjadi these flowers, that train menjadi those trains, this place menjadi these places, this student menjadi these students. Kata-kata berakhiran bunyi -s, sh, $-c h,-x$ menjadi -es, seperti that bus menjadi those buses, this dash menjadi these dashes, this watch menjadi these watches, dan that box menjadi those boxes. Kata-kata yang berakhiran huruf - $y$ yang berbunyi /i/ akan berubah menjadi -ies, seperti this baby menjadi these babies. Kata-kata berakhiran huruf $-y$ yang berbunyi selain /i/ akan menjadi -ys, seperti this day menjadi these days, that monkey menjadi those monkeys, that boy menjadi those boys (Murphy, 2014,p.26). Selain penambahan suffiks, terdapat juga bentuk jamak yang tidak beraturan, contohnya mouse (tikus) menjadi mice (tikustikus), bukan berubahh menjadi mouses. Perbedaan-perbedaan bentuk dan penggunaan deiksis inilah yang menjadi perbandingan antara deiksis ini dan itu dalam bahasa Indonesia dengan bahasa Inggris. Mahasiswa BIPA yang menguasai bahasa Inggris perlu mengenali dan melakukan penyesuaian secara berulang terhadap pembelajaran deiksis agar bahasa target dapat dikuasai dengan baik.

\section{SIMPULAN}

Deiksis ini dan itu memiliki peraturan bentuk dan penggunaan tersendiri dalam bahasa Indonesia dan bahasa Inggris. Dalam bahasa Indonesia deiksis ini dan itu memiliki ciri yang meliputi (a) deiksis digunakan sebelum kata benda atau kata kerja, (b) deiksis digunakan setelah kata benda, dan (c) deiksis digunakan untuk merujuk benda, yang bersifat tunggal dan jamak tanpa mengubah bentuk deiksis. Akan tetapi, terdapat pengulangan kata benda yang dirujuk atau didahului kata sandang pada kata benda tertentu.
Dalam bahasa Inggris, deiksis this dan that memiliki ciri yang meliputi (a) deiksis digunakan sebelum kata benda dan kata kerja, (b) deiksis this (ini) berubah menjadi these (ini) jika rujukan kata benda bersifat jamak, (c) deiksis that (itu) berubah menjadi those (itu) jika rujukan kata bendak bersifat jamak, serta (d) tidak adanya pengulangan bentuk kata benda yang dirujuk melainkan penambahan suffix. Deiksis ini dan itu, baik dalam bahasa Indonesia maupun bahasa Inggris sama-sama mengacu pada keberadaan benda. Deiksis ini menunjuk posisi obyek yang dekat, sedangkan deiksis itu menunjuk posisi obyek yang jauh. Untuk pengajar, sebaiknya saat mengajarkan materi deiksis ini dan itu agar dapat menghadirkan benda secara rill atau gambar sehingga menyajikan rujukan benda abstrak menjadi rill di hadapan mahasiswa asing. Dengan hadirnya obyek riil, pembelajaran deiksis akan lebih mudah dimengerti siswa dan pembelajaran akan lebih efektif.

\section{DAFTAR RUJUKAN}

Alarcon, J. B., \& Morales, K. N. (2011). Grammatical cohesion in students' argumentative essay. Journal of English and Literature, 2, 114-127.

Andayani. (2011). Seminar Nasional dan Launching ADOBSI, (10), 219-223

Anthony, L. (2014). AntConc (Version 3.4.3) [Computer software]. Tokyo, Japan: Waseda University.

Cummings, L. (2007). Pragmatik, Sebuah Perspektif Multidisipliner. Terjemahan oleh Eti Setiawati dkk. Yogyakarta: Pustaka Pelajar.

Kementerian Pendidikan dan Kebudayaan. (2016). Darmasiswa. Diakses dari http://darmasiswa.kemdikbud.go.id/

Ellis, R. (1986). Understanding Second Language Acquisition. New York: Oxford University Press.

Fairclough, N., \& Wodak, R. (2008). The Bologna process and the knowledgebased economy: A critical discourse analysis approach. In: Jessop B, Fairclough $\mathrm{N}$ and Wodak $\mathrm{R}$ (eds) 
Education and the Knowledge-based Economy in Europe. Amsterdam: Sense Publishers, pp.109-125.

Green, K. (2015). Deixis and the poetic persona, 1(2), 121-134.

Itaristanti. (2016). Aspek kohesi dan koherensi dalam penulisan karangan deskripsi yang disusun oleh pembelajar BIPA (Studi Kasus Mahasiswa Thammasat University, Bangkok pada Program SEA-Gate UGM 2016). Journal Indonesian Language Education and Literature, 2(1), 88-105.

Kusmiatun, A. (2016). Mengenal BIPA dan Pembelajarannya. Yogyakarta: K Media.

Lado, R. (1957). Linguistics across Cultures. Ann Arbor: University of Michigan Press.

Levinson, S. (1983). Pragmatics. Cambridge: Cambridge University Press.

Mulderrig, J. (2012). The hegemony of inclusion: A corpus-based critical discourse analysis of deixis in education policy. Discourse and Society, 23(6), 701-728.
Muliastuti, L. (2016). BIPA Pendukung Internasionalisasi Bahasa Indonesia. Makalah disajikan pada seminar Nasional Politik Bahasa di Universitas Tidar Magelang. Magelang: Untidar.

Murphy, R. (2014). Essential Grammar in Use. Cambridge: Cambridge University Press.

O'Keefe A, Clancy, B., \& Adolphs, S. (2011). Introducing Pragmatics in Use. London: Routledge.

Putrayasa, I.B. (2014). Pragmatik. Yogyakarta: Graha Ilmu.

Saddhono, K. (2012). Kajian Sosiolingustik Pemakaian Bahasa Mahasiswa Asing dalam Pembelajaran Bahasa Indonesia untuk Penutur Asing (BIPA) di Universitas Sebelas Maret. Kajian Linguistik dan Sastra, 24(2), 176-186.

Tanskanen, S. K. (2006). Collaborating towards coherence: Lexical cohesion in English discourse. Amsterdam, Netherlands: John Benjamins. 
Destiani, Andayani, \& Rohmadi, Perbamdingan deiksis pada dua buku ajar:...

\section{LAMPIRAN}

DAFTAR FREKUENSI KATA DALAM BUKU AJAR BIPA

\begin{tabular}{|c|c|c|}
\hline NO. & FREQ. & WORD \\
\hline 1 & 487 & $\mathrm{di}$ \\
\hline 2 & 462 & dan \\
\hline 3 & 322 & saya \\
\hline 4 & 271 & ini \\
\hline 5 & 226 & santi \\
\hline 6 & 187 & indonesia \\
\hline 7 & 182 & anda \\
\hline 8 & 181 & yang \\
\hline 9 & 172 & sarah \\
\hline 10 & 171 & bahasa \\
\hline 11 & 168 & apa \\
\hline 12 & 161 & dengan \\
\hline 13 & 150 & asing \\
\hline 14 & 150 & tingkat \\
\hline 15 & 149 & bagi \\
\hline 16 & 148 & dia \\
\hline 17 & 146 & penutur \\
\hline 18 & 139 & hari \\
\hline 19 & 131 & orang \\
\hline 20 & 131 & teman \\
\hline 21 & 128 & dari \\
\hline 22 & 117 & rumah \\
\hline 23 & 116 & untuk \\
\hline 24 & 113 & $\mathrm{ke}$ \\
\hline 25 & 110 & ada \\
\hline 26 & 105 & kegiatan \\
\hline 27 & 93 & sumber \\
\hline 28 & 93 & tidak \\
\hline 29 & 92 & nama \\
\hline 30 & 90 & tahun \\
\hline 31 & 86 & adalah \\
\hline 32 & 84 & bawah \\
\hline 33 & 82 & suka \\
\hline 34 & 81 & simakan \\
\hline 35 & 77 & pertanyaan \\
\hline 36 & 77 & tempat \\
\hline 37 & 69 & binatang \\
\hline 38 & 69 & kata \\
\hline 39 & 68 & bagaimana \\
\hline
\end{tabular}

\begin{tabular}{|c|c|c|}
\hline NO. & FREQ. & WORD \\
\hline 51 & 55 & tentang \\
\hline 52 & 53 & lalu \\
\hline 53 & 51 & tanggal \\
\hline 54 & 50 & sangat \\
\hline 55 & 49 & benda \\
\hline 56 & 49 & mana \\
\hline 57 & 49 & selamat \\
\hline 58 & 49 & tinggal \\
\hline 59 & 48 & berapa \\
\hline 60 & 47 & berwarna \\
\hline 61 & 46 & makanan \\
\hline 62 & 45 & berikut \\
\hline 63 & 45 & makan \\
\hline 64 & 45 & tidur \\
\hline 65 & 42 & pukul \\
\hline 66 & 41 & kosakata \\
\hline 67 & 41 & laki \\
\hline 68 & 40 & kamu \\
\hline 69 & 39 & pergi \\
\hline 70 & 39 & saja \\
\hline 71 & 39 & sampai \\
\hline 72 & 38 & dalam \\
\hline 73 & 38 & itu \\
\hline 74 & 38 & jawablah \\
\hline 75 & 38 & kabar \\
\hline 76 & 38 & senang \\
\hline 77 & 37 & aku \\
\hline 78 & 37 & atas \\
\hline 79 & 36 & ungkapan \\
\hline 80 & 35 & informasi \\
\hline 81 & 35 & sesuai \\
\hline 82 & 34 & ima \\
\hline 83 & 34 & menulis \\
\hline 84 & 34 & tua \\
\hline 85 & 34 & unit \\
\hline 86 & 33 & andini \\
\hline 87 & 33 & bulan \\
\hline 88 & 33 & pagi \\
\hline 89 & 33 & siapa \\
\hline
\end{tabular}




\begin{tabular}{|c|c|c|}
40 & 68 & kami \\
\hline 41 & 67 & jalan \\
\hline 42 & 67 & ulang \\
\hline 43 & 66 & keluarga \\
\hline 44 & 63 & com \\
\hline 45 & 59 & pada \\
\hline 46 & 58 & anak \\
\hline 47 & 58 & atau \\
\hline 48 & 58 & baik \\
\hline 49 & 58 & bandung \\
\hline 50 & 57 & juga \\
\hline
\end{tabular}

\begin{tabular}{|c|c|c|}
90 & 32 & lahir \\
\hline 91 & 32 & memberi \\
\hline 92 & 32 & percakapan \\
\hline 93 & 31 & baru \\
\hline 94 & 31 & depan \\
\hline 95 & 31 & hitam \\
\hline 96 & 30 & apakah \\
\hline 97 & 30 & barang \\
\hline 98 & 30 & guru \\
\hline 99 & 30 & panjang \\
\hline 100 & 30 & taman \\
\hline
\end{tabular}

\section{DAFTAR KONKORDANSI INI}

\begin{tabular}{|c|c|c|}
\hline NO. & \multicolumn{2}{|c|}{ KONKORDANSI INI } \\
\hline 1 & hari ulang tahunnya tahun & ini? \\
\hline 2 & ulang tahun Anda tahun & ini? \\
\hline 3 & ulang tahun Anda tahun & ini? \\
\hline 4 & Di mana letak mal & ini? \\
\hline 5 & yang dibahas pada unit & ini! \\
\hline 6 & Hendra Apa nama hari & ini? \\
\hline 7 & $\begin{array}{l}\text { berbelanja perlengkapan rumah } \\
\text { berikut }\end{array}$ & ini: A B C D \\
\hline 8 & $\begin{array}{l}2 \text { lengkapilah percakapan- } \\
\text { percakapan berikut }\end{array}$ & ini! A: Hai! Apa \\
\hline 9 & di Pizza Hut. Restoran & ini ada di antara KFC \\
\hline 10 & Pulau Jawa. Di provinsi & ini ada Pelabuhan Bakauheni yang \\
\hline 11 & 93 Sutisna. Di toko & ini ada tempat parkir, tempat \\
\hline 12 & tinggal di Jakarta. 2. Kenalkan, & ini adalah \\
\hline 13 & Kenalkan, 3. & ini adalah \\
\hline 14 & 4. Kenalkan, & ini adalah \\
\hline 15 & Kenalkan, 5. & ini adalah \\
\hline 16 & & Ini adalah Bob. Dia \\
\hline 17 & $\begin{array}{l}\text { pada pengemis. Unit } 7 \text { Simakan } \\
7.1\end{array}$ & Ini adalah foto kamar tidur \\
\hline 18 & Kaos kaki di bawah & ini adalah foto kartun Sarah. \\
\hline 19 & Anda belajar sekarang? Hari & ini adalah hari ke- ... saya \\
\hline 20 & & Ini adalah Jane. Dia \\
\hline 21 & $\begin{array}{l}\text {. No Identitas Deskripsi } 1 . \\
\text { Kenalkan, }\end{array}$ & ini adalah Joko Widodo. Dia \\
\hline 22 & dan teksturnya kenyal. Contoh: & Ini adalah makanan kesukaan Kania. \\
\hline 23 & . Cimol dari Jawa Barat. & Ini adalah makanan kesukaan semua \\
\hline
\end{tabular}




\begin{tabular}{|r|l|l|}
24 & ke Mal Boemi Kedaton. & Ini adalah mal terbesar di \\
\hline 25 & hitam. Dia tidak bersepatu. & Ini adalah Pak Badrun. Dia \\
\hline 26 & A1 83 Kegiatan 2 di bawah & ini adalah ruang tamu di \\
\hline 27 & Penutur Asing Tingkat A1 115 & Ini adalah Santi. Dia muda. \\
\hline 28 & adalah foto kartun Sarah. & Ini adalah Sarah. Dia muda. \\
\hline 29 & ini! Amin Yani AntonAnisa & Ini adalah silsilah keluarga Anisa. \\
\hline 30 & telah anda buat! Contoh: & Ini adalah silsilah keluarga saya. \\
\hline 31 & , dekat tempat tidur. Simakan 7.2. & Ini adalah toko baju anak- \\
\hline 32 & . Dia anak sulung. Lalu, & ini adik laki-laki saya, \\
\hline 33 & . Dia anak sulung. Lalu, & ini adik laki-laki saya, \\
\hline 34 & dengar! Santi : Sarah, kenalkan, & ini adik laki-laki saya, \\
\hline 35 & . Dia anak sulung. Lalu, & ini adik laki-lakisaya, namanya \\
\hline 36 & -kalimat berikut ini! 1. Kenalkan, & ini adik saya. Namanya Gina. ................. \\
\hline 37 & dengan tabel di bawah & ini! Alamat pengirim pos-el \\
\hline 38 & benda/alat & ini? Alat/benda ini untuk \\
\hline 39 & kumpulan huruf di bawah & ini! 1. Alat untuk makan. 2. Alat \\
\hline 40 & bawah silsilah keluarga berikut & ini! Amin Yani AntonAnisa Ini \\
\hline 41 & 20 Juli 1991. Sarah : Jadi, tahun & ini Anda berulang tahun pada \\
\hline 42 & dalam foto-foto berikut & ini! anda bisa bertanya pada \\
\hline 43 & -contoh pertanyaan di bawah & ini! 1. Apa kamu suka rumah \\
\hline 44 & -pertanyaan & $\begin{array}{l}\text { seperti ini! Apakah Anda suka } \\
\text { berenang? }\end{array}$ \\
\hline 45 & , namanya Siti Aminah. Yang & ini ayah saya, namanya Aris. \\
\hline 46 & , namanya Siti Aminah. Yang & ini Ayah saya, namanya Aris. \\
\hline 47 & , namanya Siti Aminah. Yang & ini ayah saya, namanya Aris. \\
\hline 48 & pertanyaan-pertanyaan di bawah & ini! 1. Bagaimana perjalanan Santi dari \\
\hline 49 & pertanyaan-pertanyaan di bawah & ini! 1. Bagaimana rumah indekos Sarah? \\
\hline 50 & $\begin{array}{l}\text { Perhatikanlah gambar-gambar } \\
\text { berikut }\end{array}$ & ini! Bagaimana sifat mereka? Kucing \\
\hline & & \\
\hline & & \\
\hline
\end{tabular}

\section{DAFTAR KONKORDANSI ITU}

\begin{tabular}{|c|c|c|}
\hline NO & \multicolumn{2}{|c|}{ KONKORDANSI ITU } \\
\hline 1 & apa yang mendukung sifatnya & itu? \\
\hline 2 & berapa persimpangan di peta & itu? \\
\hline 3 & hadiah 2 . Jelaskan apa isi & itu? \\
\hline 4 & . Di atas meja kecil & itu ada lampu duduk. Di \\
\hline 5 & yang ada di foto & itu anggota keluargaku. Sarah : Oh, \\
\hline 6 & yang ada di foto & itu anggota keluargaku. Sarah : \\
\hline 7 & taman? Bagaimana bentuk meja & itu? 10.Apa warna batu besar \\
\hline 8 & sekelas tentang apa lagu & itu! Bahasa Indonesia bagi Penutur \\
\hline 9 & $=$ memakai baju Contoh 2: Mobil & $\begin{array}{l}\text { itu bermesin diesel. Bermesin }= \\
\text { menggunakan }\end{array}$ \\
\hline
\end{tabular}




\begin{tabular}{|r|l|l|}
10 & belum mengenal k ota & itu dengan baik. Oleh karena \\
\hline 11 & ke sekolah. 10.Para pahlawan & itu _ dengan sungguh-sungguh untuk \\
\hline 12 & berbincang-bincang di bangku & itu. Di depan bangku ada \\
\hline 13 & dengan baik. Oleh karena & itu, dia meluangkan lima hari \\
\hline 14 & dicetak tebal! Kata-kata & itu disebut kata ganti. Sarah : \\
\hline 15 & Bu Inah. Dalam foto & itu, Dudung duduk di bawah. \\
\hline 16 & 93 Silakan. Sarah : & Itu foto siapa? Santi : \\
\hline 17 & 93 Silakan. Sarah : & Itu foto siapa? Santi : \\
\hline 18 & ? Santi : & itu foto teman saya. \\
\hline 19 & ?Santi : & itu foto teman saya. \\
\hline 20 & negara. Salah satu dukungan & itu ialah penyusunan bahan ajar \\
\hline 21 & A1 Kegiatan 1 Santi : & Itu kakak perempuan saya, namanya \\
\hline 22 & A1 Kegiatan 4 Santi : & Itu kakak perempuan saya, namanya \\
\hline 23 & , Kalau yang ini? Santi : & Itu kakak perempuan saya, namanya \\
\hline 24 & di lapangan. 9. Murid-murid & itu \\
\hline 25 & penyempurnaan lebih lanjut. Untuk & itu, kami sangat berterima kasih \\
\hline 26 & Tingkat A1 4. Gadis manis & itu \\
\hline 27 & yang ada di foto & itu keluargaku. $\backslash x 94$ Sarah : \\
\hline 28 & , dan pekerjaan!4. Set elah & itu, kenalkanlah teman Anda pada \\
\hline 29 & jumlah tempat atau bangunan & itu! Lalu, ceritakanlah pada teman- \\
\hline 30 & berbagai jenis teks. Selain & itu, materi dan tugas belajar \\
\hline
\end{tabular}

